\title{
Serviço Social e Política de Assistência Social: Reflexões a Partir da Perspectiva da Teoria Social Crítica
}

\author{
Social service and social assistance policy: reflections from the \\ perspective of critical social theory
}

Bruno Alvarenga Ribeiro ${ }^{1}$, Helena Rabelo Silva Garcia ${ }^{1}$.

${ }^{1}$ Centro Universitário de Formiga (UNIFOR-MG) - Formiga, Minas Gerais, Brasil.

\begin{abstract}
Resumo
Introdução: $\mathrm{O}$ artigo apresenta uma reflexão sobre a interlocução entre o Serviço Social e as políticas sociais. Maior destaque foi atribuído à interlocução com a política de assistência social, política que se constitui como espaço privilegiado para a atuação do Serviço Social. Foi feito um resgate histórico do processo de constituição das políticas sociais brasileiras e também do Serviço Social brasileiro. Esse resgate viabilizou a interlocução que se pretendeu estabelecer. Objetivo: Refletir sobre a inserção dos Assistentes Sociais no espaço sócio-ocupacional da Política Nacional de Assistência Social e sobre as contradições que perpassam essa política. Metodologia: $\mathrm{O}$ artigo está baseado em revisão bibliográfica e adotou como perspectiva teórica a Teoria Social Crítica, pois essa teoria permite fazer uma leitura crítica das contradições que colocam constrangimentos à materialização da política de assistência social. Resultados: Compreensão das contradições das políticas sociais como produtos da reprodução das relações sociais de produção. Conclusão: O Serviço Social não está livre das determinações produzidas por sua inserção na divisão sociotécnica do trabalho. Ele é requisitado a dar respostas a essas determinações comprometendo-se a fortalecer os direitos sociais.
\end{abstract}

Palavras-chave: Políticas Sociais; Serviço Social; Política de Assistência Social.

Autor correspondente:

Bruno Alvarenga Ribeiro

Endereço: R. Uruguai, 52 - Ouro Negro

Recebido em: 23/05/2016

Formiga, $M G$ - Brasil

Telefone: +553733224730

E-mail:br.alvarenga@yahoo.com.br

Revisado em: 16/08/2016

Aceito em: 18/08/2016

Publicado em: 07/12/2016 


\section{Abstract}

Introduction: The article presents a reflection on dialogue between Social Service and social policies. More emphasis was given to dialogue with the Social Assistance Policy, a policy which constitutes a privileged space for the work of the Social Service. A historical survey of the development of Brazilian social policies and also of the Social Service was carried out. This historic rescue allowed the dialogue that the article seeks to establish. Objective: Reflect on the inclusion of social workers in social and occupational space of the National Social Welfare Policy and the contradictions that pervade this policy. Methodology: The article is based on literature review. The theoretical perspective of Critical Social Theory was adopted. It is understood that this theory allows a critical reading of the contradictions that hinder the implementation of the Social Assistance Policy. Results: Understanding of the contradictions of social policies as products of the functioning of the capitalist mode of production. Conclusion: The inclusion of the Social Service in socio-technical division of labor leads to consequences: respond to situations that hinder enforcement of social rights.

Keywords: Social Politics; Social Service; Social Assistance Policy.

\section{Introdução}

A política de assistência social é um campo privilegiado para a atuação dos/as Assistentes Sociais. Tanto é verdade que pouco mais de um quinto da categoria exerce suas atividades no âmbito da assistência social ${ }^{1}$. Esses dados estão em consonância com as informações do Censo SUAS (Sistema Única de Assistência Social) de 2014. Só em CRAS (Centro de Referência de Assistência Social) são 17.567 Assistentes Sociais, o que corresponde a 43,1\% dos profissionais inseridos nesse equipamento ${ }^{2}$. Em CREAS (Centro de Referência Especializado de Assistência Social) são 5.420 Assistentes Sociais, correspondendo a 39,4\% do total de profissionais que trabalham nesse equipamento ${ }^{3}$. Somente em CRAS e CREAS existem 22.987 Assistentes Sociais trabalhando.

A grandiosidade desses números aponta para algo importante: a política de assistência se constitui como um relevante espaço sócio-ocupacional em que se inserem os profissionais do Serviço Social. Só isso já é motivo para tomar a relação entre Serviço Social e assistência social como objeto de reflexão, que é o que pretende fazer este artigo, por mais que a mesma já tenha sido objeto de incontáveis debates, mas que nunca serão suficientemente exaustivos para exaurir completamente o tema.

Sendo assim, o objeto de estudos deste ensaio tem uma dupla face: a inserção do Assistente Social no espaço sócio-ocupacional da Política Nacional de Assistência Social e as contradições que marcam tal política. Toda reflexão que se propõe está baseada em revisão bibliográfica e tem como fundamento a perspectiva teórica da Teoria Social Crítica.

A escolha dessa perspectiva é proposital, pois ela é capaz de fornecer os subsídios necessários para que seja feita uma leitura crítica das contradições que perpassam as políticas sociais, sobretudo, daquelas contradições que colocam constrangimentos à materialização da política de assistência social a partir da noção de direito social. Acredita-se que essa reflexão possa lançar luz sobre como a Teoria Social Crítica não é uma perspectiva teórica superada e de como ela se faz atual na leitura das contradições que marcam as políticas sociais brasileiras.

A melhor forma, portanto, para atender aos propósitos que se propõe, é sendo fiel a um dos principais pressupostos desta teoria: a historicidade. Dito isso é bom lembrar que a historicidade enquanto processo tem uma base material. Isso significa que as relações sociais que os homens estabelecem entre si só faz reproduzir o modo de produção, distribuição e acumulação de bens materiais e riqueza ${ }^{4}$. Não por acaso este artigo adota o resgate histórico das políticas sociais como pano de fundo de toda a reflexão sobre os pontos de interseção entre o Serviço Social e a política de assistência social.

O resgate histórico é uma das melhores formas de analisar criticamente as políticas sociais como respostas às mazelas produzidas pela subsunção do trabalho ao capital. O que significa que ele é um procedimento capaz de oferecer subsídios para uma análise do objeto em questão a partir de uma perspectiva de totalidade, que é, conforme, a Teoria Social Crítica, uma perspectiva que se preocupa em captar as múltiplas determinações que saturam a vida social $^{5}$.

A vida social só se apresenta em sua imediaticidade. A imediaticidade não coincide com as múltiplas determinações que engendram a reprodução das relações sociais contraídas entre os homens ao produzirem, distribuírem e acumularem os bens e a riqueza socialmente produzida e privadamente apropriada. Eis aí o cerne de toda a 
sociabilidade capitalista. Nessa sociabilidade, as políticas sociais cumprem uma função. Servem, sobretudo, à reprodução do que na Teoria Social Crítica é chamado de exército industrial de reserva, que é formado pela superpopulação de trabalhadores criados pelo capital com a única intenção de atender às suas necessidades, mas que são impedidos por ele de acessarem as riquezas socialmente produzidas ${ }^{4}$.

Portanto, é nesse espaço sócio-ocupacional perpassado por contradições que o profissional do Serviço Social é requisitado a atuar. Como o Serviço Social é uma profissão inserida na divisão sóciotécnica do trabalho, não está, de modo algum, livre das determinações que envolvem a reprodução das relações sociais de produção. Esse é o ponto fulcral da interseção entre as trajetórias históricas do Serviço Social e das políticas sociais, em especial da política de assistência.

Dessa forma, o resgate histórico se mostra como um modelo de tratamento dos dados que privilegia o pensamento dialético, que é um pensamento capaz de captar a realidade social em sua processualidade histórica. Essa processualidade é prenhe de contradições. Por sua vez, essas contradições assinalam, conforme indica o método críticodialético, com a possibilidade de superação da ordem do capital.

Sendo assim, o resgate histórico somado à utilização do método crítico-dialético tende a conferir a este ensaio a potencialidade da reflexão crítica que não se limita ao imediato, por isso a preocupação em compreender como algumas características foram sendo moldadas e associadas às políticas sociais brasileiras. Este trabalho destaca três: a meritocracia, a filantropia e o primeiro-damismo. É pelo circuito dessas características que a Questão Social, categoria utilizada para se referir ao conjunto das mazelas sociais produzidas pela sociedade capitalista, integra a agenda pública. Por último, antes de passar às reflexões anunciadas, é bom tecer algumas considerações sobre o método crítico-dialético.

É bom lembrar ele compõe apenas um dos fundamentos que constituem o tripé da Teoria Social Crítica de Marx. Os outros dois são a teoria do valor trabalho e a perspectiva da revolução como possibilidade histórica ${ }^{5}$. Na teoria do valor trabalho toda a criticidade necessária para perscrutar as contradições do modo de sociabilidade capitalista emerge com toda a força. Nesse sentido, é compreensível que as políticas sociais tenham uma teleologia, ou seja, tenham conforme essa teoria uma intencionalidade. Elas não emergem como produtos naturais de um tempo, mas sim como produtos históricos cuja intencionalidade é marcada por uma contradição fundamental: garantir de um lado a manutenção do modo de produção capitalista e de outro responder às demandas da classe trabalhadora organizada.
Por sua vez, a organização da classe trabalhadora faz da revolução uma possibilidade histórica, pois a ordem do capital e a luta de classes que dela faz parte oferecem elementos para a sua superação ${ }^{5}$. Pensar, portanto, a inserção do Serviço Social no espaço sócio-ocupacional da política de assistência a partir da utilização do método críticodialético, significa, acima de tudo, considerar que essa inserção é atravessada por disputas políticas que expressam as contradições que historicamente se materializaram como elementos da própria dinâmica do capital, que se opondo ao trabalho, produz mazelas que demandam a formulação de políticas sociais.

Por conseguinte, o roteiro de reflexão que ora se apresenta tem como ponto de partida e ao mesmo tempo como ponto de chegada a historicidade das políticas sociais brasileiras. Nessa historicidade foram moldadas as características que colocam obstáculos à atuação do Serviço Social no espaço sócio-ocupacional da política de assistência. Nunca é demais refletir sobre esses obstáculos, pois a saturação de conhecimentos é uma das vias para apreensão da saturação de determinações que constituem a realidade social em sua processualidade histórica, ou seja, é uma das formas de transformar, conforme a Teoria Social Crítica, o real em concreto pensado.

\section{Metodologia}

O presente ensaio foi construído a partir de consultas a fontes secundárias, o que o caracteriza como um trabalho de revisão bibliográfica. O tratamento dos dados privilegiou a adoção da Teoria Social Crítica, o que significa que o olhar utilizado está comprometido com uma análise que se volta para a apreensão das contradições que constituem o processo de institucionalização das políticas sociais como respostas às mazelas sociais produzidas pela reprodução do modo de sociabilidade capitalista.

Por último, mas não menos importante, é relevante salientar que a Teoria Social Crítica encontra os seus fundamentos numa visão de mundo e de homem baseada na concepção do materialismo histórico dialético, que tem em Marx (1818-1883) o seu grande expoente. Chauí (2000) ${ }^{6}$ esclarece o que é o materialismo histórico dialético e porque a Teoria Social Crítica de Marx está baseada nessa concepção.

É por afirmar que a sociedade se constitui a partir de condições materiais de produção e da divisão social do trabalho, que as mudanças históricas são determinadas pelas modificações naquelas condições materiais e naquela divisão do trabalho, e que a consciência humana é determinada a pensar as ideias que pensa por causa das condições materiais instituídas pela sociedade, que o pensamento de Marx [...] é chamado de materialismo histórico. ${ }^{6}$ 
Chauí ${ }^{6}$ ainda acrescenta que a concepção de Marx é materialista porque são as condições materiais que determinam o ser e o pensar e é histórica "porque a sociedade e a política não surgem de decretos divinos nem nascem da ordem natural, mas dependem da ação concreta dos seres humanos no tempo. "6. E por último, ele é dialético "por afirmar que o processo histórico é movido por contradições sociais [...]"6.

As políticas sociais, o que inclui a Política de Assistência Social, não estão livres dos condicionantes históricos que as transformam em meios de reprodução das relações sociais de produção. Ou seja, elas não são produtos naturais da ação humana. Como construções humanas elas são circunscritas historicamente, dando, dessa forma, testemunho da ação concreta dos homens no tempo, um tempo, que, aliás, é marcado indelevelmente pelas contradições que operam de um lado legitimando-as e de outro submetendo-as às insígnias do capital.

Portanto, o método crítico-dialético, método que se desdobra da Teoria Social Crítica de Marx, é o procedimento metodológico utilizado para apreender as contradições sociais que transformaram as políticas sociais e também o Serviço Social em respostas às mazelas sociais produzidas pelo modo de produção capitalista. Esse método toma o real como ponto de partida, nesse caso os pontos de interseção entre as trajetórias históricas das políticas sociais e do Serviço Social como profissão inserida na divisão sóciotécnica do trabalho, e também como ponto de chegada, nesse caso a inserção dessa profissão no espaço sócio-ocupacional de uma política social em particular: a Política Nacional de Assistência Social

\section{Discussão}

A seguir é apresentada a discussão produzida a partir do objeto selecionado para estudo: a inserção dos Assistentes Sociais no espaço sócio-ocupacional da Política Nacional de Assistência Social e as contradições que perpassam essa política. Para isso, foi necessário resgatar a trajetória histórica das políticas sociais brasileiras. Esse resgate possibilitou identificar as principais características associadas à institucionalização dessas políticas. Três delas ganharam destaque: a meritocracia, a filantropia e o primeiro-damismo. Essas características são as expressões das contradições que estão na origem da assistência social brasileira e se constituem como obstáculos para a sua materialização a partir da noção de direito social.

O Serviço Social é requisitado a intervir em meio a essas contradições. Como a política de assistência social é um importante espaço sócioocupacional ocupado pela profissão, os Assistentes Sociais são chamados a promoverem mediações que contribuam para a concretização dos direitos sociais, o que transforma o agir profissional e a política de assistência como espaço ocupacional em uma arena de disputas políticas. Essas mediações não devem ser entendidas em seu sentido habitual, o que levaria a pensar que o Assistente Social é apenas uma ponte entre a política e os demandatários dos seus serviços. Esse entendimento esvaziaria toda a pontencialidade da mediação enquanto categoria teórica, que na Teoria Social Crítica é utilizada para compreender o real em sua dialética, o que significa que ele não é estático, ou seja, o real está em constante movimento e deve ser capturado pelo pensamento como movimento, pois só assim a sua historicidade se revela e também as suas contradições ${ }^{7}$. Não existe o real compartimentalizado. A mediação rejeita a compartimentalização, pois ela esvazia a realidade social de sua significação histórica.

Portanto, o que está em jogo nas disputas travadas no âmbito da assistência social é a promoção da justiça social, o que requer do Serviço Social uma postura crítica com relação ao papel que a política cumpre na reprodução da ordem do capital. Em outras palavras, o profissional precisa promover mediações que capturem a assistência social como concreto pensado, o que significa que o pensamento, ou a razão, como queiram, deve ser capaz de inseri-la na múltipla rede determinações que saturam a vida social.

Sendo assim, este ensaio passa em seguida a uma análise que tenta empreender esforços capazes de apreenderem as políticas sociais brasileiras, em especial a política de assistência, dentro da rede de múltiplas determinações que as transformam em modos de intervenção que dão sustentabilidade ao modo de produção capitalista, participando, ao mesmo tempo, da reprodução das contradições desse modo de produção, sendo elas mesmas expressões concretas e históricas dessas contradições. Ao mesmo o tempo a reflexão vai procurar compreender os pontos de interseção entre as trajetórias históricas da política de assistência social e do Serviço Social como profissão inserida na divisão sociotécnica do trabalho.

\section{As políticas sociais e o Serviço Social em uma perspectiva histórica}

As primeiras políticas sociais brasileiras datam do início do século XX e desde a sua origem elas são marcadas por algumas características que dificultaram a sua materialização a partir da perspectiva do direito social. Algumas dessas características merecem ser destacadas, pois transformaram as políticas sociais em instrumentos de sustentação econômica do Estado e de cooptação da classe trabalhadora, são elas: a meritocracia, a filantropia e o primeiro-damismo. Pinheiro coaduna com essa assertiva ao mencionar que "[...] as políticas sociais têm sido conduzidas como parte integrante da operacionalização das engrenagens econômicas e como instrumento de sustentação política do Estado ${ }^{8}$." 
A lei Eloy Chaves, de 1923, que instituiu a caixa de aposentadoria e pensão (CAP) dos ferroviários, e é considerada a mãe do sistema previdenciário brasileiro, é um bom exemplo de como a meritocracia sempre esteve presente na gestão de políticas públicas no Brasil e as políticas sociais não fugiram a essa regra. Lembrando que a economia brasileira estava fundada desde os tempos coloniais sobre o modelo de desenvolvimento econômico agrário-exportador e que era por meio das ferrovias que se escoava toda a produção, fica fácil compreender como foi estratégico regulamentar alguns direitos trabalhistas desse setor. Benring e Boschetti lembram que

o ano de 1923 é chave para a compreensão do formato da política social brasileira no período subsequente: aprova-se a lei Eloy Chaves, que institui a obrigatoriedade de criação de Caixas de Aposentadoria e Pensão (CAPs) para algumas categorias estratégicas de trabalhadores, a exemplo dos ferroviários [...] Por que estratégicas, e consequentemente com maior poder de pressão? Naquele momento, o Brasil tinha uma economia basicamente fundada na monocultura do café voltada para a exportação - eis aqui a base da nossa heteronomia -, produto responsável por cerca de $70 \%$ do PIB nacional. Por isso os direitos trabalhistas e previdenciários foram reconhecidos para aquelas categorias de trabalhadores inseridas diretamente nesse processo de produção e circulação de mercadorias 9 .

O que predominou na regulamentação dos direitos trabalhistas da categoria profissional dos ferroviários foi o mérito que ela possuía. Isso indica que as categorias que conseguiam tensionar o Estado e os interesses da classe dominante, conseguiam obter via concessão do poder público o reconhecimento de alguns dos seus direitos. Essa análise, e os grifos na citação acima, são claros em apontarem como os primeiros modelos de políticas sociais no Brasil foram integrados à agenda pública para dar sustentabilidade ao que é próprio do modo de produção capitalista: a exploração do trabalho. Ou como queiram: a subsunção do trabalho ao capital. Não é por mero acaso que apenas algumas categorias foram contempladas com caixas de aposentadoria e pensão. A intencionalidade da concessão é muito clara: garantir a hegemonia das classes dominantes sobre as classes subalternas.

A exemplo da lei Eloy Chaves, alguns anos mais tarde, todas as outras CAP's que vieram a surgir, seguiram, invariavelmente, a mesma lógica. Eram todas políticas sociais que promoveram uma espécie de cidadania regulada, pois estiveram voltadas para os trabalhadores formalmente inseridos no mercado de trabalho. $\mathrm{O}$ termo cidadania regulada deixa transparecer que a cidadania promovida por estas políticas era bastante restrita, pois elas eram baseadas em contribuições compulsórias, ou seja, eram políticas de caráter contributivo, o que deixava de fora de sua cobertura uma grande parte da população, além de não estender, é claro, a proteção social a uma boa parte das categorias de trabalhadores.

[...] essa forma parcial e incompleta de cidadania (cidadania regulada) vai privilegiar alguns segmentos ocupacionais em detrimento do conjunto das classes subalternizadas, na medida em que exclui do padrão de proteção social e, portanto, do status de cidadania outras categorias de trabalhadores urbanos, trabalhadores informais, trabalhadores domésticos e rurais, desempregados e indigentes. Essa distinção entre cidadãos e pré-cidadãos em virtude do reconhecimento ou não de uma determinada profissão pelo Estado, não tinha outra intenção senão a de cindir e fragmentar a classe trabalhadora na sua luta por melhores condições de trabalho ${ }^{10}$.

Almeida $^{10}$ é muito feliz em sua análise. Ao indicar que o reconhecimento de algumas categorias em detrimento de outras cindiu a classe trabalhadora, a autora transcende a imediaticidade e assinala o sentido associado às políticas sociais no cenário brasileiro naquele momento, qual seja: de que o Estado estava realizando concessões aos trabalhadores. Não se trata simplesmente de concessões. Não se pode correr o risco de uma espécie de idolatria do Estado. Havia uma intencionalidade que a análise crítica deve ser capaz de capturar: conferir sustentação econômica ao Estado brasileiro e contribuir para a cooptação da classe trabalhadora.

Mais tarde, na década de 1930, durante o governo Vargas, as CAP's vão ser gradualmente extintas e serão substituídas pelos Institutos de Aposentadoria e Pensão (IAP's).

O sistema público de previdência começou com os IAPs - Institutos de Aposentadoria e Pensões -, que se expandem na década de 1930, cobrindo riscos ligados à perda da capacidade laborativa (velhice, morte, invalidez, doença), naquelas categorias de trabalhadores estratégicas, mas com planos pouco uniformizados e orientados pela lógica contributiva do seguro? .

Se nas CAP's as negociações se restringiam a patrões e empregados e podiam variar de uma empresa para outra dentro de um mesmo segmento de mercado e categoria profissional, com os IAP's os benefícios são unificados, sendo, portanto, estendidos a toda categoria profissional que os conquistasse. Mas Behring e Boschetti ${ }^{9}$ lembram que eles não eram uniformes e variavam muito de uma categoria para a outra.

Nas CAP's o financiamento dos benefícios era bipartite, sendo realizado por patrões e empregados. 
Nos IAP's o financiamento passa a ser tripartite. Dele participavam empregadores, empregados e também o Estado.

Os IAPs ofereciam um conjunto de benefícios e serviços de acordo com a contribuição dos trabalhadores, dos empresários e do Estado, que não eram uniformes e, segundo Bravo (2000), possuíam uma orientação contencionista, diga-se, estavam menos preocupados com a prestação de serviços e mais com a acumulação de reservas financeiras?.

Os IAP's promoveram um avanço, pois passaram a ser organizados por categoria profissional. Mas esse avanço não foi suficiente para romper com o traço da meritocracia, pois os benefícios continuavam a ser concedidos com base no mérito que determinada categoria profissional tinha em tensionar o Estado e os interesses das classes dominantes. Dessa maneira, fica claro que não era objetivo das políticas sociais do início do século XX promoverem o empoderamento dos trabalhadores, e a evidência mais nítida de como esse interesse esteve ausente na materialização dessas políticas é que não havia universalidade na concessão dos benefícios. Algumas categorias profissionais gozavam de alguns benefícios trabalhistas e outras simplesmente não tinham quaisquer garantias. Interessante é notar que os benefícios foram concedidos às categorias que representavam os segmentos mais importantes da economia brasileira nas primeiras décadas do século $\mathrm{XX}$ : marítimos, comerciários, bancários, industriários, servidores públicos, etc.

Dessa forma, o Estado se antecipou às mobilizações dessas categorias ao cooptá-las politicamente, evitando, assim, os custos democráticos decorrentes da luta de classes que inevitavelmente acompanharam o espraiamento do capitalismo no cenário nacional $^{11}$. Santos lembra que "[...] o capitalismo institui-se por aqui tentando minimizar "os custos democráticos" decorrentes do padrão civilizacional alcançado pela luta de classes, especialmente nas sociedades euro-ocidentais"11, o que explica, portanto, a cooptação da classe trabalhadora. Ainda é importante relembrar que a expansão das políticas sociais criou as condições para financiar a transição entre o modelo agrárioexportador e o modelo de desenvolvimento econômico que ficou conhecido como substituição de importações.

Concorre para isso uma série de fatores relacionados à crise capitalista mundial, desencadeada em 1929, que vai se prolongar até a Segunda Guerra mundial, mas também uma deliberada política nacionalista que dará início ao desenvolvimento de setores importantes da indústria de base ${ }^{11}$.
Em outras palavras, essa transição se fez necessária em função da crise econômica ocasionada pela quebra da Bolsa de Nova Iorque em 1929, crise que levou ao esgotamento o modelo agrárioexportador. Tal cenário achatou os preços dos produtos exportados pelo Brasil e elevou os preços dos produtos importados dos países do capitalismo central. Portanto, o modelo de substituição de importações surgiu como uma alternativa para contornar os efeitos da crise.

A dificuldade de importar, devido à recessão mundial, estimulou a produção nacional que, utilizando a capacidade anteriormente instalada, passou a satisfazer a demanda interna não afetada pela crise. Dessa forma, a indústria substitutiva de importações ganhou espaço em relação à atividade exportadora, e as variáveis dinâmicas da economia passam a ser endógenas, com o crescimento voltado para o mercado interno ${ }^{8}$.

Sendo assim, uma das primeiras iniciativas foi realizar investimentos para criar um parque industrial que fosse capaz de produzir os bens que antes eram importados. Feito isso, foi necessário elevar o poder de consumo da classe média. Tal feito foi alcançado com a concessão de benefícios trabalhistas para as categorias profissionais estratégicas para a economia brasileira. Portanto, é nesse sentido que se pode afirmar que as políticas sociais brasileiras serviram para conferir sustentação econômica ao Estado, além obviamente de também conferirem sustentação política, pois foram utilizadas como moedas de troca em barganhas realizadas com os trabalhadores.

É notável, dessa maneira, para restituir à análise crítica das políticas sociais nesse período a perspectiva de totalidade, que as concessões de benefícios aos trabalhadores tinham a explícita intenção de garantir a reprodução das relações sociais de produção, marcadas, ao que se sabe, pelas contradições que se originam da exploração da força de trabalho. Essa é a perspectiva que não pode ser perdida de vista pelo Serviço Social, caso contrário, a profissão cai no lugar comum de reproduzir o fetiche de que existe coincidência entre imediaticidade e totalidade. A totalidade transcende ao imediato. Conforme Sant'ana e Silva,

contida na dinâmica da vida social, esta categoria é componente da realidade, embora não se revele, imediatamente, como tal. A realidade é rica em determinações, saturada de múltiplas mediações que explicam a dinâmica de complexos sociais materialmente existentes (trabalho, classe social, consciência, ideologia, pauperismo, entre outros). Ela, todavia, se expressa apenas imediatamente na esfera da vida cotidiana, como um complexo aparentemente simples, que elimina - na sua forma sensível-mediata - o processo que a explica e a constitui ${ }^{5}$. 
Um fato digno de nota é que os benefícios trabalhistas cobriam apenas uma pequena parcela da população. Quem se encontrava fora do mercado de trabalho contava apenas com a filantropia da Igreja Católica ou com as ações caritativas empreendidas pelas diversas instituições filantrópicas que recebiam do Estado os recursos para se manterem. A LBA (Legião Brasileira de Assistência) foi uma dessas instituições, criada em 1942 para ajudar as famílias dos soldados enviados à Segunda Guerra Mundial, e por "força do destino" acabou assumindo posteriormente o carro chefe da assistência social brasileira, pois a ela coube coordenar o repasse de recursos para as demais instituições filantrópicas. A LBA teve como fundadora a primeira-dama Darcy Vargas e mesmo após a Segunda Guerra Mundial manteve operante o seu trabalho de filantropia. Mas depois de protagonizar alguns escândalos de corrupção durante a gestão da primeira dama Rosane Collor a LBA foi extinta no primeiro dia de governo do presidente Fernando Henrique Cardoso em 1995.

Essa instituição foi criada para atender às famílias dos pracinhas envolvidos na Segunda Guerra e era coordenada pela primeira-dama, Sra. Darci Vargas, o que denota aquelas características de tutela, favor e clientelismo na relação entre Estado e sociedade no Brasil, atravessando a constituição da política social. Posteriormente, a LBA vai se configurando como instituição articuladora da assistência social no Brasil, com uma forte rede de instituições privadas conveniadas, mas sem perder essa marca assistencialista, fortemente seletiva e de primeiro-damismo, o que só começará a se alterar muito tempo depois, com a Constituição de $1988^{9}$.

Resulta desse breve histórico o entendimento de que as refrações da Questão Social integraram a agenda pública brasileira via o circuito da meritocracia, da filantropia e do primeiro-damismo, sendo, dessa forma, desconectadas dos fatores responsáveis por sua determinação: a apropriação privada dos meios de produção e a exploração do trabalho como mercadoria. É bom abrir um pequeno parêntese para entender a função cumprida pelo trabalho no capitalismo, que é de ser uma mercadoria cuja exploração produz mais-valia.

[...] a multiplicação do capital só é possível devido a apropriação de grande parte dos frutos do trabalho assalariado. O operário, com seu trabalho, gera riquezas superiores ao salário que recebe. Está claro que a multiplicação do capital só é possível devido à exploração do trabalho humano. $\mathrm{O}$ capitalista é capitalista porque aumenta o seu capital às custas da exploração do trabalho assalariado ${ }^{12}$.

O excedente de trabalho, ou seja, a riqueza que o trabalhador produz e que excede o salário que ele recebe, é conhecido como mais-valia. Resulta disso o enriquecimento dos detentores dos meios de produção, que são os capitalistas, e o empobrecimento dos trabalhadores. A compreensão desse processo ajuda a entender a relação entre o que é chamado de Questão Social e a exploração do trabalho enquanto mercadoria. Essa relação faz da Questão Social, ou melhor, dizendo, de suas refrações, algo circunscrito historicamente. E o que a meritocracia, a filantropia e o primeiro-damismo fizeram foi integrarem a Questão Social na agenda pública pela via da sua desistoricização. Assim, fechando o parêntese, fica a interrogação: o que é a Questão Social?

Por Questão Social se entende

o conjunto das expressões das desigualdades da sociedade capitalista madura, que tem uma raiz comum: a produção social é cada vez mais coletiva, o trabalho torna-se mais amplamente social, enquanto a apropriação dos seus frutos mantém-se privada, monopolizada por uma parte da sociedade ${ }^{13}$.

Essa definição é importante porque ela circunscreve as desigualdades sociais como fenômenos históricos, como o são também as respostas dadas a esses fenômenos. Uma das respostas analisadas por este texto são as políticas sociais. Outra resposta são as profissões gestadas para administrá-las e para responderem às refrações da Questão Social, como é, por exemplo, o caso do Serviço Social. Sendo assim, as políticas sociais e o Serviço Social têm a mesma raiz: a Questão Social. Se por um lado é verdade que a socialização cada vez mais ampliada da produção e a apropriação privada dos seus frutos estão no cerne da Questão Social, por outro, deve ser lembrado que os seus contornos ganham maior clareza com a entrada do operariado no cenário político da sociedade capitalista. Disso resulta que

sua emergência vincular-se-ia ao surgimento do capitalismo e à pauperização do trabalhadores, e sua constituição, enquanto questão política, foi remetida ao século XIX, como resultado das lutas operárias, donde o protagonismo político da classe trabalhadora - à qual se creditou a capacidade de tornar públicas as suas precárias condições de vida e trabalho, expondo as contradições que marcam historicamente a relação entre capital e o trabalho ${ }^{4}$.

$\operatorname{Mota}^{4}$ não poderia ser mais clara ao se referir ao protagonismo da classe trabalhadora na definição dos contornos políticos da Questão Social. A entrada do operariado no cenário político da sociedade capitalista deu relevo às contradições produzidas historicamente a partir da subsunção do trabalho ao capital. Dessa maneira, a crítica das políticas sociais, feita é claro em uma perspectiva de totalidade, o que é primordial para não menosprezar suas significações 
históricas, deve estar vinculada à compreensão das respostas dadas pelo Estado capitalista às necessidades do capital e ao atendimento das demandas da classe trabalhadora. Trocando em miúdos, a crítica das políticas sociais deve ser feita à luz da compreensão dos fatores que estão na gênese da Questão Social, ou melhor dizendo, que estão na gênese de suas refrações. Ainda sobre a Questão Social e suas refrações, Machado assinala que

como toda categoria arrancada do real, nós não vemos a questão social, vemos suas expressões: o desemprego, o analfabetismo, a fome, a favela, a falta de leito em hospitais, a violência, a inadimplência, etc. Assim é que, a questão social só se nos apresenta nas suas objetivações, em concretos que sintetizam as determinações prioritárias do capital sobre o trabalho, onde o objetivo é acumular capital e não garantir condições de vida para toda a população ${ }^{14}$.

Portanto, as políticas sociais e o Serviço Social são respostas aos tensionamentos gerados pelas refrações da Questão Social, que reverberaram sobre os interesses das classes dominantes, que por sua vez se apropriaram do Estado e de seus mecanismos de enfrentamento desses tensionamentos.

Isso quer dizer que o Serviço Social não esteve livre da prática da caridade. Seu surgimento está alinhado a essas práticas engendradas pela Igreja Católica, por instituições filantrópicas e também às necessidades do Estado em incorporar à sua agenda mecanismos para promover a mediação dos conflitos produzidos pelos embates entre capital e trabalho, papel que coube às políticas sociais, sejam as de caráter contributivo, como nos casos dos benefícios trabalhistas, sejam as de caráter não contributivo, cujo caso mais ilustrativo são as ações caritativas que se espraiaram por toda sociedade brasileira graças ao apoio do Estado que as manteve centralizadas no governo federal por meio da LBA.

Só com o Movimento de Reconceituação que o Serviço Social brasileiro se afastou de suas bases conservadoras. Esse movimento se materializou por uma série de encontros, que entras décadas de 1960 e 1980, ressignificaram o Serviço Social em toda a América Latina ${ }^{15}$. O seu maior saldo foi a aproximação do Serviço Social com relação a Teoria Social Crítica de Marx, que acabou resultando na formulação do projeto ético-político da profissão. $\mathrm{O}$ projeto é ético porque assume como sua bandeira a luta dos trabalhadores por seus direitos e é político porque empreende esforços para empoderar a classe trabalhadora no seu movimento de fazer frente aos mandos do capital.

É importante destacar que a aproximação com a Teoria Social Crítica reconceituou o Serviço Social em muitos aspectos. Um dos aspectos mais relevantes é a eleição da Questão Social como objeto de estudos e intervenção da profissão. Outro aspecto é a proximidade estabelecida com a classe trabalhadora, que teve como saldo positivo a incorporação da categoria trabalho ao arsenal teórico do Serviço Social $^{16}$. Tudo isso dotou o Serviço Social de criticidade. É essa criticidade que não pode desaparecer dos horizontes da profissão, caso, contrário, a atuação profissional no espaço sócioocupacional da política de assistência corre o risco de reproduzir as características que marcaram historicamente as políticas sociais brasileiras, características que já foram assinaladas e analisadas quanto às suas funcionalidades com relação às necessidades do Estado capitalista brasileiro. Portanto, a reconceituação do Serviço Social é balizadora de uma atuação crítica e comprometida com as necessidades dos trabalhadores e não com os anseios do capital.

Na década de 1980, a reconceituação do Serviço Social se fez evidente por meio de diversas frentes. Uma delas foi a participação da categoria na constituinte que aprovou a Constituição Federal de 1988 (CF/88), o que é indicativo de que a profissão se inseriu no caldo cultural dos movimentos que lutaram por políticas sociais pensadas a partir da perspectiva do direito social, luta representativa do afastamento estabelecido pelo Serviço Social com relação às suas bases conservadoras.

A CF/88 inovou com relação a todas as constituições anteriores, principalmente ao assegurar que os direitos sociais são um dever do Estado em um direito do cidadão. Além do mais, a $\mathrm{CF} / 88$ inseriu a assistência social no tripé da seguridade social, que é formado, ainda, por duas outras políticas: saúde e previdência social. Isso representou um grande avanço, pois, ao menos em tese, rompeu com as práticas clientelistas que dominavam as políticas sociais brasileiras desde os seus primórdios. Ao menos em tese, pois a assistência social levou cinco anos para ser regulamentada em forma de lei, o que aconteceu somente em 1993 com a promulgação da Lei Orgânica da Assistência Social (LOAS).

No entanto, a LOAS foi aprovada em um contexto marcado pelo avanço da ofensiva neoliberal e pela reforma do Estado. A reforma do Estado foi um conjunto de medidas de caráter macroeconômico que foram tomadas para seguir o receituário do Consenso de Washington, que ocorreu em 1989. Do Consenso de Washington resultaram algumas orientações para que os países do capitalismo periférico pudessem continuar acessando os empréstimos das agências financiadoras internacionais, entre elas o FMI (Fundo Monetário Internacional). "Essas orientações foram, na sua totalidade, apontadas pelo Consenso de Washington para serem aplicadas nos países e economias periféricas, condicionando, inclusive a ajuda financeira dos organismos internacionais ao compromisso com o receituário" ${ }^{\text {17. }}$. 
Dentre as orientações resultantes do Consenso de Washington estavam a desregulamentação dos direitos trabalhistas e o investimento em políticas sociais de caráter compensatório, ou seja, políticas residuais cuja única finalidade é amortecer os impactos das políticas macroeconômicas. É necessário compreender as políticas compensatórias para além do imediato, pois se por um lado elas permitem o acesso a uma renda mínima, garantindo, assim, o direito ao consumo, pedra angular do modo de produção capitalista, por outro, elas substituem o trabalho como elemento integrador à sociedade ${ }^{4}$. O direito ao trabalho é substituído pelo direito ao consumo. O que está em jogo é que o trabalho enquanto elemento integrador, historicamente e dialeticamente "oportunizou o surgimento de concentrações de trabalhadores e sua organização político-sindical"18, ou seja, o trabalho se constitui como uma unidade de contrários, o que quer dizer que por meio dele a exploração é engendrada, mas também por meio dele a classe trabalhadora é empoderada para fazer frente aos mandos do capital.

Essa análise pode, portanto, ser aplicada à assistência social na atualidade, pois a maior parte do orçamento da seguridade social vem sendo destinado mais aos programas de transferência de renda do que aos serviços socioassistenciais, o que quer dizer que a política de assistência vem se configurando como uma política social compensatória ${ }^{19}$. Esse é o tipo de análise crítico-dialética tornada possível pela utilização dos referenciais da Teoria Social Crítica, análise que esclarece ao Serviço Social o tipo de obstáculo que deve ser enfrentado pela profissão no espaço sócio-ocupacional da política de assistência.

Ainda sobre as políticas sociais compensatórias é necessário esclarecer que elas funcionam conforme a lógica do redistributivismo, o qual aposta que as desigualdades sociais podem ser resolvidas na esfera da circulação de mercadorias e não na esfera de produção, o que faz ocultar a natureza do modo de produção capitalista ${ }^{20}$. É, portanto, no cenário de espraiamento dessas políticas que emerge a figura do Estado ajustador, que

[...] direciona o gasto social para os grupos mais necessitados, de forma a amortecer a implementação das políticas de ajuste, operacionalizando o novo modelo econômico por meio da preservação do tecido social e, portanto, da capacidade de governo; da consolidação de uma imagem externa favorável e otimista para a atração de capitais estrangeiros; e da compatibilização com estruturas clientelísticas de manutenção do poder ${ }^{8}$.

O Estado ajustador e as políticas sociais por ele adotadas chocaram-se com a orientação da LOAS e com a CF/88, e o Programa Comunidade Solidária, criado em 1995, e presidido pela primeira dama Dona Ruth Cardoso, é um exemplo claro desse conflito que inviabilizou a materialização da assistência social a partir da perspectiva do direito social. Além do mais, o programa deu uma sobrevida ao primeiro-damismo sempre tão presente na gestão das políticas sociais brasileiras, mas não somente a ele, como também à filantropia. É bom que se diga, que o primeirodamismo é uma característica tão marcante das políticas sociais brasileiras, que mesmo na política de assistência - uma política teoricamente orientada pela perspectiva do direito social, pelo menos nos moldes que assume atualmente -, é possível notar a sua presença. Mas agora ele aparece com uma nova roupagem, pois as primeiras-damas têm buscado "[...] formação acadêmica para assumir o lugar de coordenação da assistência social e se capacitarem para a gestão pública da área" ${ }^{21}$. Isso representa uma afronta aos "[...] princípios básicos da administração pública, como a impessoalidade, a legalidade, a publicidade, a probidade, o concurso público e a prestação de contas $[\ldots]^{\prime 21}$.

Dessa feita, o primeiro-damismo, somado ao assistencialismo e à filantropia, representa um grande desafio para a implementação da assistência social a partir da perspectiva do direito, perspectiva que o Programa Comunidade Solidária simplesmente desprezou e o fez ignorando o texto da LOAS e atropelando a $\mathrm{CF} / 88$. Desse modo, é importante fazer menção ao conceito de direito social para que se possa realizar uma análise mais crítica do que representou o Comunidade Solidária e de como a sobrevida que ele conferiu ao primeiro-damismo, à filantropia e ao assistencialismo coloca obstáculos para a materialização da política de assistência como política de direito e gera, ao mesmo tempo, desafios para a atuação profissional do/a Assistente Social no espaço sócio-ocupacional da assistência social. Com relação ao conceito de direito social, Couto esclarece:

Compõe o direito social a ideia de que as dificuldades enfrentadas pelos homens para viver com dignidade serão assumidas coletivamente pela sociedade, com supremacia da responsabilidade do Estado, que deverá criar um sistema institucional capaz de dar conta dessas demandas ${ }^{17}$.

Não foi o que aconteceu com o Programa Comunidade Solidária, ou seja, com ele não foi criado um sistema institucional cuja administração foi tomada como dever supremo do Estado. O Programa Comunidade Solidária focou suas ações em populações que se encontravam em situação de pobreza e extrema pobreza, adotando para isso um recorte focalista, ou seja, um recorte de renda que estabelecia os critérios para ser atendido pelo programa. Tal recorte contrariava o que estabelecia a LOAS: a criação de uma política de assistência social de caráter universal, o que pressupõe a primazia da responsabilidade do Estado em sua implementação e a presença em territórios em que o público-alvo da política necessite acessar os serviços, benefícios, programas e projetos por ela ofertados. 
Sobretudo, é importante dar relevo ao fato de que o Programa Comunidade Solidária esteve fundamento em ações que tinham como base $o$ assistencialismo. Essas ações promoveram a desresponsabilização social do Estado, pois transferiram para a sociedade, através do apelo à solidariedade, a incumbência de condução das políticas sociais ${ }^{19}$. É em meio a toda essa ambiência histórica marcada pelo apelo à solidariedade, à filantropia e ao voluntariado, que vai sendo construída a assistência social brasileira, e ela não saiu ilesa ${ }^{19}$. É notório, então, que o referido programa deu mais do que uma sobrevida ao primeirodamismo, que ainda se faz presente na política de assistência. Ele também acentuou o fisiologismo político na assistência social e promoveu a sua refilantropização, andando, dessa maneira, na contramão da luta por uma política de assistência pensada a partir da lógica do direito, o que pressupõe a primazia da responsabilidade do Estado.

Embora vinculado à Casa Civil da Presidência da República, o Programa Comunidade Solidária nunca teve um caráter universal, ou seja, as ações que ele promovia eram descontinuadas, pois na lógica eram empreendidas por uma rede assistencial formada por instituições filantrópicas e não por equipamentos públicos. O programa era uma espécie de atualização da LBA, coordenando o repasse de recursos para instituições que se responsabilizavam pela promoção da "nova caridade". Ele foi extinto em 2002, tendo sido substituído pelo Programa Fome Zero. Portanto, das décadas iniciais do século XX aos anos iniciais do século XXI, as políticas sociais brasileiras foram indelevelmente marcadas pelo assistencialismo.

É interessante abrir um parêntese para deixar registrado que o assistencialismo, a filantropia e o primeiro-damismo colocam obstáculos ao enfrentamento da Questão Social, que é algo do qual o Serviço Social não pode fugir. Mota afirma que só existe um caminho, que é o de imprimir à atuação profissional uma direção social estratégica ${ }^{4}$.

[...] como a realidade não pode ser enquadrada em formatações e deduções lógicas e sim apreendida através da identificação das suas contradições, o que podemos defender é que, apesar das determinações sociais da profissão, é possível imprimir uma direção social estratégica à prática profissional, expressa numa direção intelectual e política inclusiva ${ }^{4}$.

O Serviço Social precisa se comprometer com uma atuação profissional que não esvazie a Questão Social de todo o seu sentido crítico. Para isso, o seu enfrentamento deve estar alinhado a uma direção ideológica referenciada pelo projeto ético-político da categoria, o que implica na decisiva escolha pelo empoderamento da classe trabalhadora, principalmente em tempos tão marcados pela precarização do trabalho, que exige do Estado, por meio de suas mediações, nesse caso a política de assistência, que assuma não somente os inaptos para o trabalho, mas também os aptos. E não é essa uma das mais contundentes expressões da Questão Social? Ou seja,

[...] na impossibilidade de garantir o direito ao trabalho - quer pelas condições que assume o trabalho no capitalismo, quer pelo nível de desemprego estrutural no qual nos encontramos, ou, ainda, pela orientação da política econômica posta em prática no país - o Estado amplia seu campo de atuação na medida em que também assume os $\operatorname{aptos}^{19}$.

Desdobra-se desse raciocínio o entendimento de que "[...] em tempos de crise, os pobres sobre os quais incide a assistência social são: os miseráveis, desempregados, desqualificados para o trabalho, os trabalhadores precarizados, além dos tradicionalmente inaptos para as tarefas laborais. "19. Fechando o parêntese, é hora de retornar ao quadro em que emergiu a formulação da Política Nacional de Assistência Social nos anos iniciais do século XXI, que veio dar materialidade à LOAS, que fora promulgada em 1993.

Em 2004 o Conselho Nacional de Assistência Social aprovou uma resolução que normatizou a implementação da Política Nacional de Assistência Social a partir da perspectiva do Sistema Único de Assistência Social (SUAS). É bom lembrar que um ano antes a IV Conferência Nacional de Assistência Social havia deliberado sobre a criação do SUAS, que começa a ser implementado a partir de 2005. Desde, então, a Política Nacional de Assistência Social vem sendo implementada, juntamente com os equipamentos do SUAS, os CRAS e os CREAS, que dão materialidade a essa política. Como não poderia ser diferente, a política de assistência social acabou se transformando num dos principais espaços sócioocupacionais em que o Serviço Social se faz presente, algo que é confirmado pelos dados do Censo SUAS 2014. Os 22.987 Assistentes Sociais atuando em CRAS e CREAS apontam para a importância da política de assistência como espaço sócioocupacional em que se insere o Serviço Social. Aliás, historicamente, as políticas sociais sempre foram um campo privilegiado para a atuação do Serviço Social, pois como já foi analisado, o Serviço Social e as políticas sociais surgiram como respostas às refrações da Questão Social, e até o momento da sua reconceituação, a profissão foi apenas uma executora dessas políticas.

No que se refere à política de assistência social e sua ocupação enquanto espaço sócio-ocupacional pelo Serviço Social, Sposati destaca que

pouco mais do que um quinto da categoria, está desempenhando sua atividade em âmbito municipal 
na política de assistência social. Seguramente uma política que envolve um quinto de uma categoria profissional deve ser campo de análise privilegiado para pesquisa $[\ldots]^{1}$.

Todavia, essa é uma ocupação que não se faz sem tensões. As tensões são de diversas ordens. Para entendê-las é bom recobrar a reconceituação vivida pelo Serviço Social a partir da década de 1980, reconceituação que resultou na formulação do projeto ético-político da profissão, já mencionado anteriormente. Por sua vez, este projeto profissional tem como fundamento o projeto societário de superação da ordem do capital, que exige do Assistente Social uma postura crítica com relação a todas as estratégias utilizadas pelo capital para se reproduzir, e dentre elas está a reprodução da classe que vive do trabalho, sobretudo, dos trabalhadores que estão inseridos no exército industrial de reserva.

$\mathrm{O}$ exército industrial de reserva é formado pelo contingente de trabalhadores que não estão inseridos no mercado de trabalho e sua função é garantir o achatamento salarial daqueles que estão trabalhando. "Ao referir-se à classe trabalhadora, engloba-se aí tanto a parcela dessa classe diretamente inserida no mercado de trabalho, como aquele excedente para as necessidades médias de exploração do capital: o exército industrial de reserva" 22 .

E é aí que entra a política de assistência social. Embora essa política represente um avanço, pois eleva a assistência social à condição de direito, rompendo, dessa forma, com a lógica do assistencialismo, sua função é clara: reproduzir o exército industrial de reserva. Iamamoto e Carvalho assinalam que uma das funções das políticas sociais é socializarem o custo de reprodução do exército industrial de reserva:

Os capitalistas, embora impelidos a partilhar dos custos de reprodução dessa população, tentam, na medida do possível, desincumbir-se de tal ônus, ampliando a penúria desses trabalhadores "livres", reduzidos a condições de vida infra-humanas, e socializando os custos de reprodução desse segmento da classe trabalhadora para o conjunto da sociedade, no que as políticas sociais dos Estados capitalistas desempenham um papel fundamental ${ }^{22}$.

A evidência de que política de assistência social assume essa função se materializa no público-alvo atendido por ela, formado por populações que estão na eminência de terem seus laços familiares e comunitários rompidos ou que em muitos casos já foram desfeitos por causa principalmente da ausência de trabalho e também de acesso a renda, mas não somente por isso. Sendo assim, o objetivo primordial da política de assistência social é prover as condições para a manutenção dos laços familiares e comunitários, pois entende-se que o ser humano se constitui principalmente a partir desses laços. Um parêntese: essa não é a única evidência de que a assistência social assume a função de reproduzir o exército industrial de reserva. Outra forte evidência é a sua assistencialização, que em nada guarda relação com o assistencialismo que marcou as políticas sociais anteriores à $\mathrm{CF} / 88$ e também o Programa Comunidade Solidária.

[...] essa discussão da assistencialização fixa-se com muita facilidade na assistência exatamente porque ela assume a parte assistencial das outras políticas. Logo, o que chamamos de "assistencialização" é justamente aquilo que a Assistência Social faz, mas não deveria fazer ${ }^{23}$.

A reflexão de Couto chama atenção para algo que vem acontecendo e que tem afetado o tripé da seguridade social $^{23}$. As mudanças no mundo do trabalho têm ocasionado a precarização das relações trabalhistas e o achatamento da renda dos trabalhadores. Em tese o trabalhador que está no mercado de trabalho deveria poder contar com a proteção social da previdência social. No entanto, com o achatamento da sua renda, resta a esse trabalhador recorrer à assistência social, que se transforma numa espécie de porto seguro da classe trabalhadora, que constrangida pelas mudanças no mundo do trabalho fica na eminência de ter seus laços familiares e comunitários rompidos. Siticovsky aponta que esse fenômeno tem relação com a crise da sociedade salarial, que expulsa trabalhadores do mercado através da eliminação de postos de trabalho, o que configura o desemprego estrutural e transforma o trabalho assalariado e protegido em peça de museu $^{19}$. No entanto, não cabe à assistência social se transformar em política de promoção ao trabalho. É bom lembrar o que diz Couto: a assistência se transforma em porto seguro, mas não deveria assumir tal função, pois ao assumi-la ela contribui para o esvaziamento das outras políticas que constituem o tripé da seguridade social ${ }^{23}$.

Preservando, portanto, os laços familiares e comunitários ou ajudando a restaurá-los, a política de assistência social está ajudando a reproduzir o exército industrial de reserva. Então essa é uma das contradições que atravessam a política e que exige dos seus técnicos de referência um olhar atento, principalmente dos Assistentes Sociais, que em função de seu projeto ético-político assumem como compromisso o empoderamento da classe trabalhadora, indiferentemente de ela se encontrar ou não no mercado de trabalho. Como empoderar essas pessoas no espaço sócio-ocupacional de uma política cuja função é a manutenção do exército industrial de reserva? Não por acaso a gestão da política de assistência tem como princípio a ideia dos mínimos sociais, princípio inscrito no primeiro artigo da LOAS. Esse princípio reproduz o cerne da ofensiva neoliberal: o mínimo para os trabalhadores e o máximo para o capital. Ao comentar a respeito da 
ofensiva neoliberal, Couto menciona o seguinte: "no campo político, o Estado deveria ser fortalecido naquilo que fosse necessário para manter o funcionamento do mercado, criando um movimento minimax, no qual os investimentos seriam mínimos para o trabalho e máximos para o capital (Sader, 2000). $" 17$.

Sobretudo, é importante evidenciar que o princípio dos mínimos sociais se materializa por meio dos constrangimentos orçamentários que marcam a gestão da política de assistência social. Uma política cuja pretensão é preservar os laços familiares e comunitários e garantir aos sujeitos e famílias por ela atendidos o acesso a bem-estar social, precisa conferir aos seus técnicos as condições para realizarem os enfrentamentos das situações que impedem a efetivação dos direitos dos seus usuários. Mas como esses técnicos, entre eles o Assistente Social, conseguem realizar esses enfrentamentos se a sua condição de trabalho é marcada pela precarização? Pelo que se sabe a maior parte dos técnicos da política ainda são contratados por modalidades de trabalho que pouco incluem a realização de concursos públicos. Ainda persistem as contratações por meio de processos seletivos simplificados e até mesmo por meio de processos licitatórios. Isso precariza a gestão do trabalho no âmbito da Política de Assistência Social, produzindo ainda prejuízos de ordem técnica e financeirooperacional.

Embora se saiba que a flexibilização das relações de trabalho que se faz acompanhada da precarização das formas de contratação não se constitua uma prerrogativa da Política de Assistência Social, nessa Política os prejuízos de ordem técnica e financeiro-operacional decorrentes dessas situações são ainda mais significativos. Isto em razão das consequências nefastas que rebatem sobre um público já historicamente excluído de bens e serviços produzidos $[\ldots]^{24}$.

Por sua vez, a precarização do trabalho se faz perceber através da rotatividade de profissionais:

[...] no âmbito do trabalho pode-se identificar uma grande rotatividade de profissionais, implicando em desperdício de recursos em capacitação considerando-se os constantes recomeços com novas demandas de qualificação para as mesmas funções $[\ldots]^{24}$.

Portanto, a implantação do SUAS, que dá materialidade à Política de Assistência Social,

[...] exige novas formas de regulação e gestão do trabalho e, certamente, a ampliação do número de trabalhadores com estabilidade funcional é condição essencial, ao lado de processos continuados de formação e qualificação, a partir do ingresso via concurso público, definição de carreiras e de processos de avaliação e progressão, caracterização de perfis das equipes e dos serviços, além da remuneração compatível e segurança no trabalho ${ }^{25}$.

Diante de todas as considerações realizadas, fica evidente que uma leitura da política de assistência com base na Teoria Social Crítica é condição necessária para evidenciar suas contradições e dar visibilidade ao papel por ela desempenhado na mediação dos direitos sociais. É tal leitura que torna explícito como essa política atua nos processos de reprodução da sociabilidade capitalista, algo que só pode acontecer quando ela é capturada em sua rede de determinações, o que implica, em última instância, considerar a sua historicidade, que é uma manifestação singular da processualidade histórica de uma sociedade marcada pela soberania do capital.

Portanto, ao recobrar a trajetória histórica das políticas sociais, o que incluiu um olhar sobre a história da política de assistência, este artigo pôde demonstrar como essas políticas são respostas às sequelas produzidas pela soberania do capital, o que exigiu a formatação de profissões para administrá-las. É com a intencionalidade de administrar as refrações da Questão Social que surgiu o Serviço Social. Sendo assim, a profissão não esteve livre dos determinantes produzidos por sua inserção na divisão sóciotécnica do trabalho. Por conseguinte, essa inserção exige do Assistente Social um olhar crítico-dialético com relação ao seu exercício profissional e aos modos como tal exercício se materializa nos diferentes espaços sócio-ocupacionais.

\section{Conclusão}

As reflexões apresentadas estão longe de esgotar todas as contradições que fazem parte do universo das políticas sociais brasileiras, o que inclui a política de assistência. No entanto, elas são suficientes para apontarem que essas contradições são um reflexo da reprodução do modo de sociabilidade capitalista, que ao reproduzir o capital, cria ao mesmo tempo as condições que demandam intervenções para minimizarem as sequelas geradas pelos ajustes de caráter macroeconômico.

Tais condições requisitam a presença do Serviço Social, que sendo uma profissão inserida na divisão sóciotécnica do trabalho, não está, portanto, livre das determinações produzidas por essa inserção. Que saída resta ao Serviço Social? Apropriar-se dos referenciais da perspectiva da Teoria Social Crítica para capturar o real para além de suas manifestações imediatas. Não é uma tarefa fácil. Todavia, ela se faz necessária e urgente para garantir que as políticas sociais efetivem os direitos sociais regulamentados por elas.

Fica, portanto, evidente que ao se apropriar da Teoria Social Crítica o Serviço Social tem condições 
de apreender o real que constitui a política de assistência social para além da sua imediaticidade. Isso aponta para algo importante: a Teoria Social Crítica não é uma perspectiva teórica superada. A prova disso é que ela mune o Serviço Social com o arsenal teórico para compreender que a historicidade é um elemento essencial na formação da realidade social. Não por acaso este ensaio adotou a perspectiva histórica como fio condutor de suas reflexões.

Esse fio condutor só faz revelar a base material que dá sustentáculo para as relações sociais contraídas entre os homens. Mais do que isso, ele revela que a reprodução da vida material, o que compreende a produção, a distribuição e a acumulação de bens e riqueza, não se faz sem contradições. Por sua vez, essas contradições são reafirmadas e ao mesmo tempo ocultadas por mediações que fazem desaparecer o que está além do imediato: a lógica da exploração do trabalho. Não menos importante é entender que essa lógica produz toda a sorte de mazelas sociais que demandam a formulação de políticas sociais.

Sendo assim, as políticas sociais, o que inclui a política de assistência social, cumprem o papel de remendarem o tecido social sob a ordem do capital, produzindo, dessa maneira, a impressão de que ele é uniforme e coeso. Mas toda uniformidade e coesão não passam de uma ilusão. A meritocracia, o primeiro-damismo e a filantropia são materializações oriundas dos procedimentos que criam essa ilusão. Ao Serviço Social cabe desnudar as mediações que historicamente transformam a ilusão em dado real, conferido, portanto, à classe trabalhadora e aos demandatários das políticas sociais o empoderamento necessário ao enfrentamento de todos os desdobramentos produzidos pela subsunção do trabalho ao capital.

Essa é, por conseguinte, a única via para o entendimento da Questão Social como elemento da dinâmica do capital. Não há perspectiva de materialização dos direitos sociais sem esse entendimento. A materialização dos direitos sociais requer acima de tudo um adensamento da "[...] ação do Serviço Social junto às lutas sociais revolucionárias, alternativa que se confrontaria com os limites da divisão sociotécnica do trabalho [... $]^{\prime 4}$. Os desafios estão postos, mas não falta arsenal para enfrentá-los, e eles podem ser encontrados nos pressupostos da Teoria Social Crítica.

Todavia, resta esclarecer que essa não é uma luta de uma única categoria. No entanto, é evidente que se trata de uma luta da qual o Serviço Social não pode fugir, caso contrário, estará esvaziando o seu objeto de estudos e intervenção de todo o seu conteúdo histórico. Perdendo a referência de um objeto historicizado a profissão abriria a mão da crítica da própria atuação profissional e dos efeitos produzidos sobre essa atuação a partir da sua inserção na divisão sóciotécnica do trabalho.

\section{Agradecimentos}

As reflexões apresentadas resultam de revisão bibliográfica que subsidia a realização da pesquisa de iniciação científica intitulada: "Serviço Social e Sistema Único de Assistência Social: um estudo com Assistentes Sociais do município de Formiga/MG”. A pesquisa está em andamento e encontra-se vinculada ao Programa de Iniciação Científica do UNIFOR-MG (PIBIC/FAPEMIG/UNIFOR-MG). Ela conta ainda com o apoio da Fundação de Amparo à Pesquisa de Minas Gerais (FAPEMIG). Os autores externam os seus agradecimentos à FAPEMIG e ao UNIFORMG.

\section{Declaração de conflitos de interesses}

Os autores do artigo afirmam que não houve nenhuma situação de conflito de interesse, tais como propostas de financiamento, emissão de pareceres, promoções ou participação em comitês consultivos ou diretivos, entre outras, que pudessem influenciar no desenvolvimento do trabalho.

\section{Referências}

1 - SPOSATI, A. Pesquisa e produção do conhecimento no campo do Serviço Social. Revista Katálysis, v. 10, n. esp. p. 15-25, 2007.

2 - BRASIL. Ministério do Desenvolvimento Social e Combate à Fome. Censo SUAS 2014 resultados nacionais: Centro de Referência da Assistência Social. Brasília, DF, 2015a.

3 - BRASIL. Ministério do Desenvolvimento Social e Combate à Fome. Censo SUAS 2014 resultados nacionais: Centro de Referência Especializado de Assistência Social. Brasília, DF, 2015b.

4 - MOTA, A. E. Questão Social e Serviço Social: um debate necessário. In: MOTA, A. E. (Org.). O Mito da Assistência Social: ensaios sobre Estado, Política e Sociedade. 4 ed. São Paulo: Cortez, 2010.

5 - SANT'ANA, R. S.; SILVA, J. F. S. da. O método na Teoria Social de Marx: e o Serviço Social: Temporalis, ano 13, n. 25, p. 181-203, jan./jun. 2013.

6 - CHAUÍ, M. Convite à Filosofia. São Paulo: Ática, 2000 .

7 - ZACARIAS, I. R. A Influência da Teoria Marxiana no Trabalho do Assistente Social. 139 p. Dissertação (Mestrado em Serviço Social) Pontifícia Universidade Católica do Rio Grande do Sul, Porto Alegre, 2013.

8 - PINHEIRO, V. C. Modelos de desenvolvimento e políticas sociais na América Latina em uma perspectiva histórica. Planejamento e políticas públicas, n. 12, p. 6388, jun./dez. 1995. 
9 - BeHRING, E. R.; BOSCHETTI, I. Política social: fundamentos e história. São Paulo: Cortez, 2009.

10 - ALMEIDA, E. T. V. de. Assistência Social e cidadania: um diálogo necessário. Vértices, v. 6 , n. 1, p. 27-63, jan./abr. 2004.

11 - SANTOS, J. S. “Questão Social”: particularidades no Brasil. São Paulo: Cortez, 2012.

12 - SOUZA, A. I.; MARCHI, L.; MACHADO, M. I. O trabalho no capitalismo: alienação e desumanização. Curitiba: CEFURIA, 2006.

13 - IAMAMOTO, M. B. O Serviço Social na contemporaneidade: trabalho e formação profissional. 20 ed. São Paulo: Cortez, 2011.

14 - MACHADO, E. EM. Questão Social: objeto do Serviço Social? Serviço Social em revista, Londrina, v. 2, n. 2, p. 39-47, Jul./Dez. 1999.

15 - RIBEIRO, B. A.; SILVA, A. M. Da institucionalização do Serviço Social na América Latina à inserção da Questão Social na agenda pública: reflexões sobre o Movimento de Reconceituação. In: SEMINÁRIO AMÉRICA LATINA: CULTURA, HISTÓRIA E POLÍTICA, 2015, Uberlândia. Anais... Uberlândia: Pueblo/UFU, 2015. Disponível em: $<$ http://seminarioamericalatina.com.br/eixo1/> Acesso em: 8 jul. 2015.

16 - RIBEIRO, B. A.; SILVA, A. M.; TEIXEIRA, K. F. O Serviço Social em uma perspectiva histórica: os saldos do movimento de reconceituação. In: SEMINÁRIO NACIONAL DE SERVIÇO SOCIAL, TRABALHO E POLÍTICA SOCIAL, 2015, Florianópolis. Anais... Florianópolis: UFSC, 2015. Disponível em: <http://ppgss.ufsc.br/files/2016/06/Trabalhos_Eixo-I.zip> Acesso em: 8 jul. 2015.

17 - COUTO, B. R. O direito social e a Assistência Social na sociedabe brasileira: uma equação possível? São Paulo: Cortez, 2008.

18 - MOTA, A. E. A centralidade da Assistência Social na Seguridade Social brasileira nos anos 2000. In: MOTA, A. E. (Org.). O Mito da Assistência Social: ensaios sobre
Estado, Política e Sociedade. 4 ed. São Paulo: Cortez, $2010 \mathrm{~b}$.

19 - SITCOVSKY, M. Particularidades da expansão da assistência social no Brasil. In: MOTA, A. E. (Org.). O Mito da Assistência Social: ensaios sobre Estado, Política e Sociedade. 4 ed. São Paulo: Cortez, 2010.

20 - BEHRING, E. R. Política social no capitalismo tardio. 6 ed. São Paulo: Cortez, 2015.

21 - YASBEK, M. C.; MESTRINER, M. L; CHIACHIO, N. B., RAICHELIS, R.; PAZ, R.; NERY, V. O Sistema Único de Assistência Social em São Paulo e Minas Gerais: desafios e perspectivas de uma realidade em movimento. In: COUTO, B. R.; YASBEK, M C.; SILVA, M. O. da S.; RAICHELIS, R. (Orgs). O Sistema Único de Assistência Social no Brasil: uma realidade em movimento. 2 ed. São Paulo: Cortez, 2011.

22 - IAMAMOTO, M. V.; CARVALHO, R. de. Relações sociais e Serviço Social no Brasil: esboço de uma interpretação histórico-metodológica. 19 ed. São Paulo: Cortez, 2006.

23 - COUTO, B. R. Assistência Social em debate: direito ou assistencialização? In: CONSELHO FEDERAL DE SERVIÇO SOCIAL (CFESS) (ORG.). Seminário nacional o trabalho do/a Assistente Social no SUAS. Brasília: CFESS, 2011.

24 - ARAÚJO, C. C; PEREIRA, M. E. F. D; GUILHON, M. V. M; SOUSA, S. de M. P. S. Implantação e implementação do Sistema Único de Assistência Social (SUAS) nos estados do Pará, Maranhão e Pernambuco: uma análise dos resultados de pesquisa empírica. In: COUTO, B. R.; YASBEK, M C.; SILVA, M. O. da S.; RAICHELIS, R. (Orgs). O Sistema Único de Assistência Social no Brasil: uma realidade em movimento. 2 ed. São Paulo: Cortez, 2011.

25 - COUTO, B. R.; YASBEK, M. C.; RAICHELI, R. A Política de Assistência Social e o SUAS: apresentando e problematizando fundamentos e conceitos. In: COUTO, B. R.; YASBEK, M C.; SILVA, M. O. da S.; RAICHELIS, R. (Orgs).. O Sistema Único de Assistência Social no Brasil: uma realidade em movimento. 2 ed. São Paulo: Cortez, 2011 